\title{
Citrate and the Conversion of Carbohydrate into Fat
}

\author{
ACTIVITIES OF CITRATE-CLEAVAGE ENZYME AND ACETATE THIOKINASE \\ IN LIVERS OF NORMAL AND DIABETIC RATS
}

\author{
BY MELODEE S. KORNACKER AND J. M. LOWENSTEIN \\ Graduate Department of Biochemistry, Brandeis University, Waltham, Mass., U.S.A.
}

(Received 2 October 1964)

\begin{abstract}
1. The activity of citrate-cleavage enzyme declines in alloxan-diabetes. 2. The administration of insulin elevates the activity of the enzyme in livers of normal and diabetic animals. Diets high in glucose or fructose elevate the activity of citrate-cleavage enzyme in normal animals, whereas only the diet high in fructose does so in diabetic animals. These observations parallel the effects of insulin, glucose and fructose on fatty acid synthesis in normal and diabetic animals. The effect of fructose is brought into play more rapidly and is larger than the effect of glucose. 3. With one exception acetate thiokinase shows similar changes at a lower level of activity. 4. The results indicate that insulin acts by increasing glucose utilization, and not by exerting a direct effect on citrate-cleavage enzyme or acetate thiokinase.
\end{abstract}

Fatty acid synthesis from labelled glucose, fructose, lactate and acetate is severely depressed in diabetes. On the other hand, the oxidation to carbon dioxide of fructose, lactate and acetate is unimpaired. This shows that in diabetes there is a block in fatty acid synthesis beyond glucose phosphorylation (Stetten \& Boxer, 1944; Brady \& Gurin, 1950; Chernick \& Chaikoff, 1951; Chernick, Chaikoff \& Abraham, 1951; Chaikoff, 1953; Wieland, Neufeldt, Numa \& Lynen, 1963). Fatty acid synthesis in diabetic animals can be restored by giving insulin (Chernick \& Chaikoff, 1950; Brady, Lukens \& Gurin, 1951; Renold, Hastings, Nesbett \& Ashmore, 1955; Lequin \& Steyn-Parvé, 1962). It can also be restored without giving insulin by feeding with a diet high in fructose (Baker, Chaikoff \& Schusdek, 1952).

Evidence has been presented previously that indicates an involvement of citrate-cleavage enzyme in fatty acid synthesis. For example, when starved rats are re-fed with a diet high in carbohydrate the activity of citrate-cleavage enzyme of liver rises 15 -fold above normal values. Re-feeding with a diet high in fat leads to little or no increase in the activity of the enzyme, whereas re-feeding with a balanced diet leads to increases intermediate between these two extremes. Acetate thiokinase shows similar changes, but on a smaller scale (Kornacker \& Lowenstein, 1963, 1965). The activity of hepatic citrate-cleavage enzyme of hereditarily obese mice is $3 \cdot 3$-fold greater than that of their non-obese siblings. On the other hand, the activity of acetate thiokinase is the same in both types of mice (Kornacker \& Lowenstein, 1964a). It was proposed that, at the concentrations of citrate that prevail in the cell, the reaction catalysed by citrate-cleavage enzyme may be one of the ratelimiting steps of fatty acid synthesis (Kornacker \& Lowenstein, 1963).

Evidence is now presented that the activity of citrate-cleavage enzyme is diminished in the liver of diabetic rats. The effects of insulin and of diets high in glucose or fructose on the activities of citratecleavage enzyme in livers of normal and diabetic rats are described. Preliminary accounts of this work have appeared (Kornacker \& Lowenstein, $1964 b$; Lowenstein, Spencer \& Kornacker, 1964).

\section{EXPERIMENTAL}

High-speed supernatants prepared from sucrose homogenates of rat liver were assayed for the activities of citratecleavage enzyme and acetate thiokinase. The acetohydroxamate assay was used for both enzymes. Details of these methods were described by Kornacker \& Lowenstein (1965). The hydroxylamine hydrochloride used in our reaction mixture was neutralized to $\mathrm{pH} 7.5$ with $\mathrm{NaOH}$. After the present work had been completed we read that high concentrations of $\mathrm{Na}^{+}$have an inhibitory effect on acetate thiokinase (Korff, 1953). When $\mathrm{Na}^{+}$in our reaction mixture was replaced by $\mathrm{K}^{+}$, acetate-thiokinase activity increased 2.5-fold. This ratio was the same regardless of the nutritional or hormonal state of the animal. All acetatethiokinase activities reported in the present paper have been multiplied by $2 \cdot 5$. The activity of citrate-cleavage enzyme remained the same when $\mathrm{Na}^{+}$was replaced by $\mathrm{K}^{+}$. Rats 
that had been starved for $48 \mathrm{hr}$. were made diabetic by intraperitoneal injection of alloxan monohydrate (Mann Research Laboratories Inc., New York, N.Y., U.S.A.). A freshly prepared aqueous solution (100 mg./ml.) was injected at a dosage of $100 \mathrm{mg} . / \mathrm{kg}$. The animals were placed in individual metabolism cages 1 week after this treatment. About $60 \%$ were found to have polyuria. Analyses for urinary glucose (Park \& Johnson, 1949) showed that the animals with polyuria excreted 3-13g. of glucose/day. These are subsequently referred to as diabetic rats. Normal rats and those not affected by alloxan excreted less than 0.03 g. of glucose/day. Protamine-zinc-insulin was obtained from Eli Lilly and Co., Indianapolis, Ind., U.S.A. Unless otherwise indicated rats were given a balanced diet (Wayne Lab-Blox; Allied Mills, Chicago, U.S.A.). The high-glucose diet was that described by Kornacker \& Lowenstein (1965). The high-fructose diet had the same composition, except that glucose was replaced by fructose.

\section{RESULTS}

Effect of insulin on citrate-cleavage enzyme and acetate thiokinase in diabetic rats. Induction of alloxan-diabetes leads to a $2 \cdot 5$-fold decrease in citrate cleavage and a 2 -fold decrease in acetate activation. The low levels of activity persist for at least 5 months. As shown below, the difference between citrate-cleavage activity in normal and diabetic animals is much greater when the animals are maintained on a diet high in glucose instead of the normal diet. In both short-term and long-term diabetic animals, the activity of the citrate-cleavage enzyme is restored to normal in less than a day after a single injection of insulin (Table 1).

The effect of administering insulin to diabetic animals over a period of 6 days is shown in Fig. 1 .

Table 1. Activities of citrate-cleavage enzyme and acetate thiokinase in livers of rats with alloxandiabetes

Where indicated animals were given 10 units of protamine-zinc-insulin subcutaneously $19 \mathrm{hr}$. before enzyme assay. The mean of six values for normal animals is shown for comparison.

$\begin{array}{lccc}\begin{array}{l}\text { Duration } \\ \text { of diabetes }\end{array} & \text { Remarks } & \begin{array}{c}\text { Citrate } \\ \text { cleavage }\end{array} & \begin{array}{c}\text { Acetate } \\ \text { activation }\end{array} \\ \text { 1 week } & - & 0.29 & 0 \cdot 13 \\ \text { 3 weeks } & - & 0.09 & 0 \cdot 10 \\ \text { 1 month } & - & 0 \cdot 18 & 0 \cdot 30 \\ \text { 2 months } & - & 0 \cdot 20 & 0 \cdot 32 \\ \text { 3 months } & - & 0 \cdot 21 & 0 \cdot 27 \\ \text { 5 months } & - & 0 \cdot 21 & 0 \cdot 30 \\ \text { 3 weeks } & \text { Plus insulin } & 0.60 & 0 \cdot 32 \\ \text { 5 months } & \text { Plus insulin } & 0.71 & 0.32 \\ \text { Nil } & \text { Normal animals } & 0.50 & 0.47\end{array}$

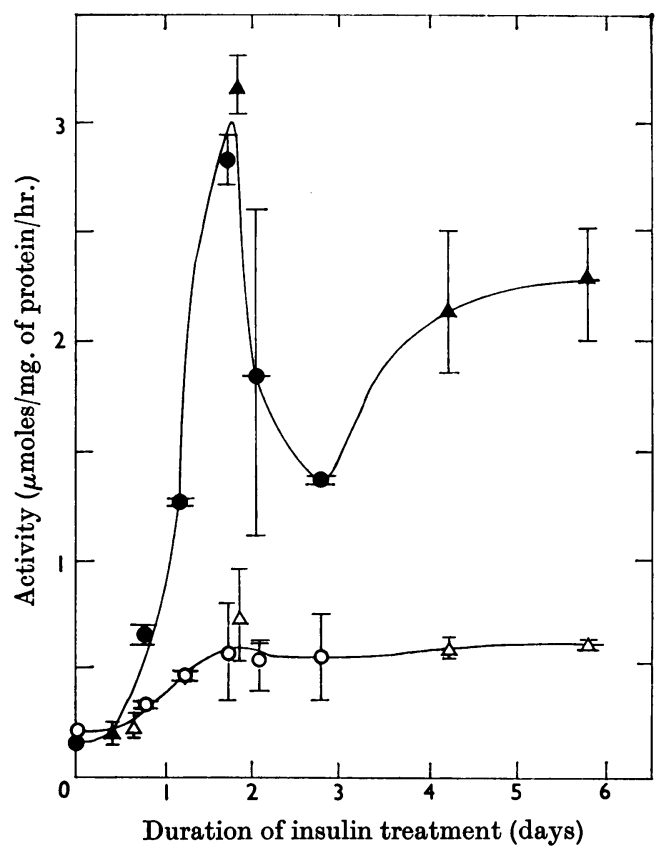

Fig. 1. Effect of protamine-zinc-insulin on the activities of citrate-cleavage enzyme ( $\bullet$ and $\boldsymbol{\Delta}$ ) and acetate thiokinase $(O$ and $\Delta$ ) in high-speed supernatant of rat liver. The amount of insulin given was 30 units $/ \mathrm{kg}$. given once a day $(\Delta$ and $\Delta$ ) or twice a day ( $\bullet$ and $O$ ). Values for day 0 are average activities of six animals. The number of animals (two or three) used for the other points are indicated by the horizontal lines, the vertical lines showing the ranges.

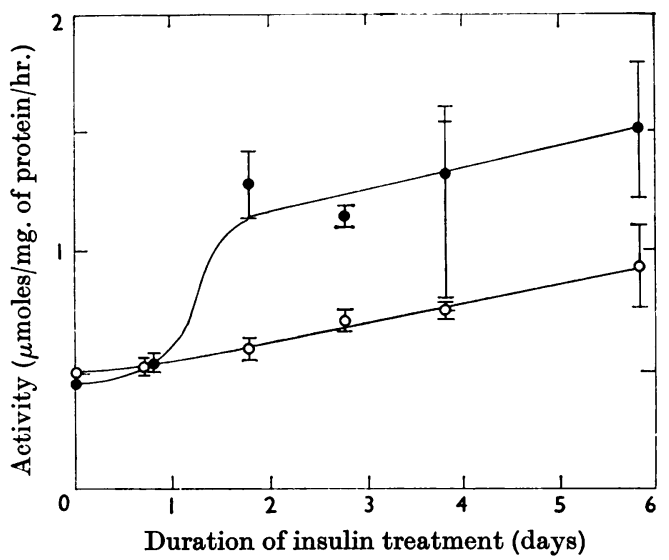

Fig. 2. Effect of protamine-zinc-insulin ( 30 units/kg./day) on the activities of citrate-cleavage enzyme $(\bullet)$ and acetate thiokinase $(O)$ in high-speed supernatant of rat liver. Values for day 0 are average activities of ten animals. The numbers of animals (two or three) used for the other points are indicated by the horizontal lines, the vertical lines showing the ranges.

Bioch. 1965, 95 
There is a 15-fold increase in the activity of citratecleavage enzyme and a $2 \cdot 5$-fold increase in the activity of acetate thiokinase over a period of $40 \mathrm{hr}$. Thereafter the activity of citrate-cleavage enzyme levels off at a value approx. 11 times that found in diabetic animals and 4.5 times that found in normal animals. The activity of acetate thiokinase, on the other hand, levels off at a value that is the same as that found in normal animals.

The effect of administering insulin to normal animals is shown in Fig. 2. After 6 days, the activity of citrate-cleavage enzyme is 3 -fold greater than normal, and that of acetate thiokinase is $\mathbf{1 . 8}$-fold greater than normal. The increase in citratecleavage activity in the normal animals is not as rapid as in the diabetic animals. This may be due to the presence of compensating mechanisms in normal animals that are absent at the start of the insulin injections in diabetic animals.

The amount of insulin used in these experiments greatly exceeds the amount needed to stop excretion of glucose and restore the concentration of blood sugar to normal. However, it has been shown that, even when the amount of insulin administered is held to the minimum required to restore sugar concentrations in blood and urine to normal, the synthesis of fatty acids is still elevated considerably above normal (Lequin \& Steyn-Parvé, 1962).

Effect of high-glucose diet. When normal animals kept on the balanced diet are placed on a diet high

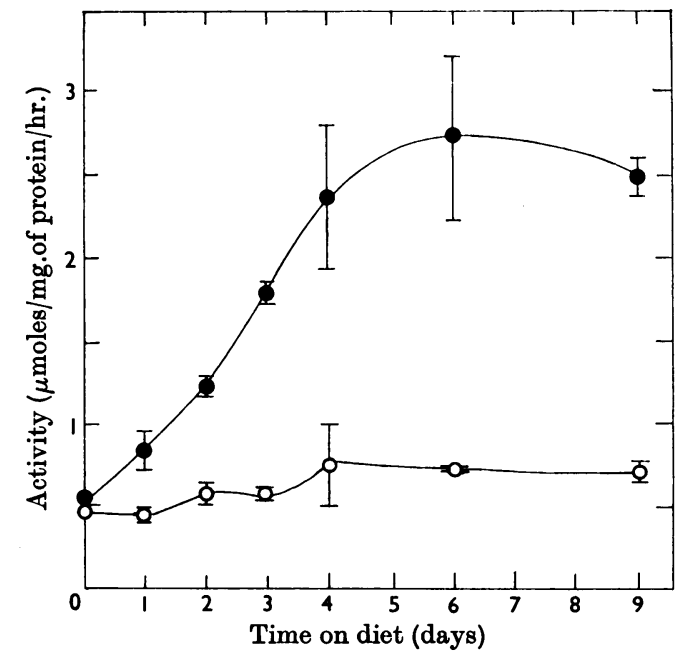

Fig. 3. Effect of transferring normal animals from a balanced diet to a diet high in glucose and low in fat on the activities of citrate-cleavage enzyme (৩) and acetate thiokinase (O) in high-speed supernatant of rat liver. Values for day 0 are average activities of ten animals. Other points are averages of two animals, the vertical lines showing the ranges. in glucose and low in fat, there is a 5-fold increase in the activity of citrate-cleavage enzyme and a $1 \cdot 5$-fold increase in the activity of acetate thiokinase over a period of 4 days (Fig. 3). Thereafter the activities of the enzymes remain approximately constant for the next 5 days.

When diabetic animals are placed on the diet high in glucose, the activity of citrate-cleavage enzyme increases only 2-fold over a period of several days. This change does not suffice to restore the activity to levels found in normal animals fed on the balanced diet. On the other hand, there is an almost 5-fold increase in the activity of acetate thiokinase (Fig. 4). After the diabetic animals have been kept on the high-glucose diet for 2-5 days the activity of acetate thiokinase is greater than that of citrate-cleavage enzyme. This is the only instance where we have observed acetate-thiokinase activity to be appreciably greater than citrate-cleavage activity.

The ratio of activities for normal and diabetic rats that have been on the diet high in glucose for 5 days is $\mathbf{8}$ for citrate-cleavage enzyme but only 0.7 for acetate thiokinase (Figs. 3 and 4). This indicates that citrate cleavage but not acetate activation depends on hexose utilization.

Effect of high-fructose diet. When normal animals kept on the balanced diet are placed on a diet high in fructose and low in fat there is a 9-fold increase in the activity of citrate-cleavage enzyme and a 2 -fold increase in the activity of acetate thiokinase over a period of 4 days (Fig. 5). Thereafter the activities of the enzymes remain approximately

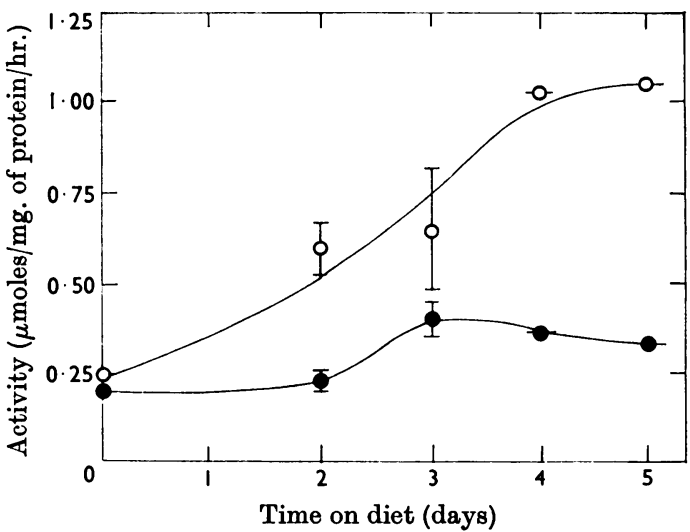

Fig. 4. Effect of transferring diabetic animals from a balanced diet to a diet high in glucose and low in fat on the activities of citrate-cleavage enzyme (๑) and acetate thiokinase (O) in high-speed supernatant of rat liver. Values for day 0 are average activities of six animals. Other points are averages of two animals, the vertical lines showing the ranges. 


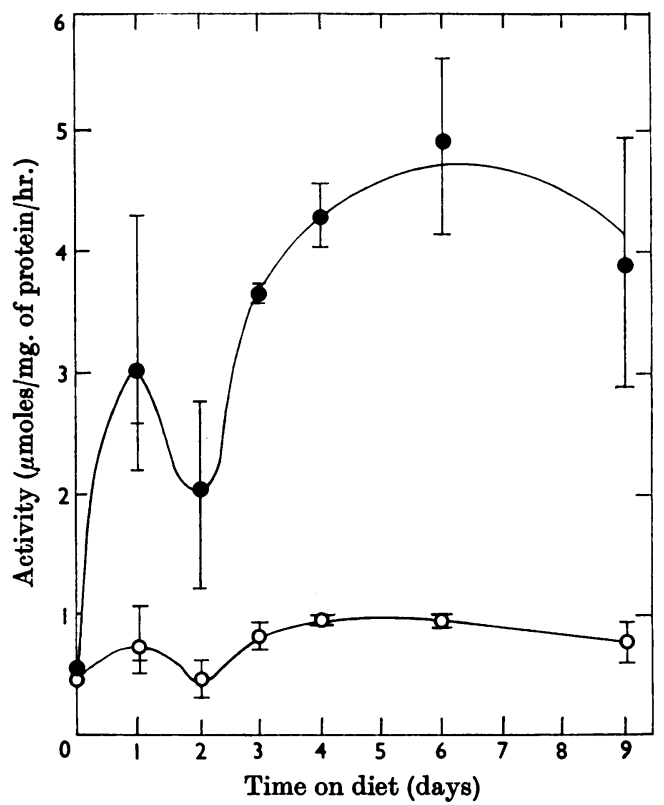

Fig. 5. Effect of transferring normal animals from a balanced diet to a diet high in fructose and low in fat on the activities of citrate-cleavage enzyme (O) and acetate thiokinase (O) in high-speed supernatant of liver. Values for day 0 are average activities of ten animals. The numbers (two or three) of animals used for the other points are indicated by the horizontal lines, the vertical lines showing the ranges.

constant for the next 5 days. Fructose therefore exerts a greater effect on citrate-cleavage activity than does glucose. This is particularly noticeable on the first day after starting the new diet. With fructose the enzyme activity is elevated 6-fold, whereas with glucose the enzyme activity is elevated only $1 \cdot 7$-fold.

The most striking difference, however, is observed when diabetic animals kept on the balanced diet are placed on the diet high in fructose (Fig. 6). The activity of citrate-cleavage enzyme increases 19-fold over a period of 3 days, and that of acetate thiokinase increases about 4-fold. Compared with the effect of fructose, the effect of glucose on diabetic animals is negligible (Figs. 4 and 6). The change in citrate-cleavage activity in fructose-fed diabetic rats is in harmony with the unimpaired utilization of fructose by these animals.

\section{DISCUSSION}

Insulin elevates the activity of citrate-cleavage enzyme in livers of normal and diabetic animals (Figs. 1 and 2). Diets high in glucose or fructose elevate the activity of citrate-cleavage enzyme in

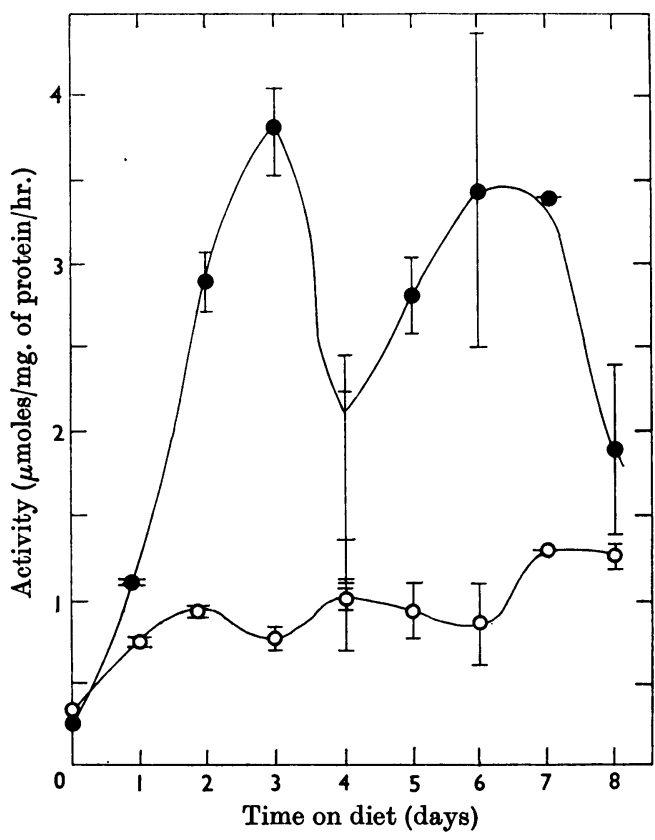

Fig. 6. Effect of transferring diabetic animals from a balanced diet to a diet high in fructose and low in fat on the activities of citrate-cleavage enzyme (0) and acetate thiokinase $(O)$ in high-speed supernatant of liver. Values for day 0 are averages of six animals. The numbers (two or four) of animals used for the other points are indicated by the horizontal lines, the vertical lines showing the ranges.

normal animals (Figs. 3 and 5), but only the diet high in fructose elevates the activity of citratecleavage enzyme in diabetic animals (Figs. 4 and 6). These results are consistent with the view that the activity of citrate-cleavage enzyme depends on the degree of carbohydrate utilization. Impaired utilization of glucose is a characteristic of diabetic animals, and this has been shown to result from a negligibly low activity of glucokinase in diabetic rats (Sharma, Manjeshwar \& Weinhouse, 1963; Viñuela, Salas \& Sols, 1963; Blumenthal, Abraham \& Chaikoff, 1964; Walker \& Rao, 1964). Utilization of fructose is not impaired in diabetic animals (for references see Beatty \& West, 1955). Since the diet high in fructose produces a large increase in citrate-cleavage activity of diabetic rats in the absence of insulin, it follows that insulin does not exert a direct effect on citrate-cleavage enzyme. In each of these nutritional and hormonal changes the activity of citrate-cleavage enzyme changes in the manner expected of an enzyme involved in fatty acid synthesis.

Acetate-thiokinase activity shows changes similar to that of citrate-cleavage enzyme, but the changes 
are smaller and at a lower level of activity. An exception to this is the activity of acetate thiokinase in diabetic animals receiving the diet high in glucose. In this instance acetate-thiokinase activity surpasses citrate-cleavage activity (Fig. 4). However, under these conditions citrate-cleavage activity is quite low.

The results suggest that glucose and fructose in normal animals, and fructose in diabetic animals that lack insulin, produce a substance that stimulates the production of citrate-cleavage enzyme and probably other enzymes of fatty acid synthesis. The substance may be $\alpha$-glycerophosphate, which has been shown to stimulate fatty acid synthesis in vitro (Howard \& Lowenstein, 1964). $\alpha$-Glycerophosphate may serve to remove a feed-back inhibitor such as long-chain acyl-CoA. This in turn could lead to the de-repression of synthesis of citratecleavage enzyme and other enzymes of fatty acid synthesis. Alternatively, but less likely, $\alpha$-glycerophosphate may act as an inducer.

The effect of fructose is brought into play more rapidly and is larger than the effect of glucose (Figs. 3 and 5), although intestinal absorption of fructose proceeds at only about half the rate observed for glucose (Cori, 1925). Fructose is also more antiketogenic than glucose, and it has been suggested that the main antiketogenic effect of fructose and sorbitol is to promote esterification of fatty acids (Exton \& Edson, 1964). One possible explanation is that $\alpha$-glycerophosphate is formed more rapidly from fructose than from glucose.

Fitch, Hill \& Chaikoff $(1959 a, b)$ measured the activities of five enzymes that metabolize glucose 6-phosphate in the livers of normal and diabetic rats. This work was later extended to 14 other enzymes (Fitch \& Chaikoff, 1962). Comparisons were made between animals fed on a normal diet and those fed on diets high in glucose or fructose. It was concluded that livers of diabetic rats have a diminished ability to respond to substitution of a normal diet by diets high in glucose or fructose. Though this is true for some enzymes, Figs. 5 and 6 show that this is not true for citrate-cleavage enzyme in animals maintained on a diet high in fructose.

Liver slices from diabetic rats show a greatly decreased rate of fatty acid synthesis, but they oxidize fructose, lactate, acetate and octanoate to carbon dioxide at a normal rate, and synthesize cholesterol at a rate greater than normal. These results were interpreted as showing that the metabolic defect of fatty acid synthesis in diabetes is distinct from the defect in glucose phosphorylation and occurs subsequent to the formation of acetylCoA (Brady \& Gurin, 1950; Chernick \& Chaikoff, 1951 ; Chernick et al. 1951; Hotta \& Chaikoff, 1952 ; Folley \& Greenbaum, 1960). We propose a new interpretation of these findings that is based on the intracellular 'compartmentation' of acetyl-CoA. The degradation of carbohydrate and fat leads to the formation of intramitochondrial acetyl-CoA whereas the new synthesis of long-chain fatty acids is predominantly an extramitochondrial process (Harlan and Wakil, 1963; Spencer, Corman \& Lowenstein, 1964). For fatty acid synthesis to take place the acetyl group of intramitochondrial acetyl-CoA must be diverted into the extramitochondrial space of the cell (Spencer \& Lowenstein, 1962; Bhaduri \& Srere, 1963; Lowenstein, 1963; Kornacker \& Lowenstein, 1964a). The Results section shows that one of the metabolic defects in the liver of diabetic animals is the greatly diminished formation of extramitochondrial acetyl-CoA by citrate-cleavage enzyme. According to this interpretation the production and oxidation of intramitochondrial acetyl-CoA can remain unimpaired, and excess of acetyl-CoA can be diverted into acetoacetate formation.

Pathways that do not involve citrate in the transfer of acetyl groups from the mitochondria to the cell sap were discussed by Kornacker \& Lowenstein (1965). One of these involves carnitine as carrier of the acetyl group (Bremer, 1962; Fritz, 1963). Measurements of the rate of incorporation of the acetyl group of acetylcarnitine into fatty acids, and of the activity of extramitochondrial acetyl-CoA-carnitine acetyltransferase, show that this enzyme is not sufficiently active to account for the rates of fatty acid synthesis in liver and lactating mammary gland of rat (Lowenstein, 1965).

The specific activities of citrate-cleavage enzyme reported in the Results section are very similar to those reported by Shrago, Lardy, Nordlie \& Foster (1963) for malic enzyme in high-speed supernatants of livers from normal and diabetic rats with and without insulin. Shrago et al. (1963) also showed that adrenalectomy, and adrenalectomy followed by the administration of cortical steroids, has little or no effect on the activity of malic enzyme. The same has been found to be true of citrate-cleavage enzyme (A. F. Spencer \& J. M. Lowenstein, unpublished work). The activities of malic enzyme in livers of diabetic rats fed on diets high in glucose or fructose are 0.25 and 1.34 units respectively (Fitch \& Chaikoff, 1962) (1 unit $=1 \mu$ mole/mg. of high-speed-supernatant protein/hr.). This compares with activities of citrate-cleavage enzyme of 0.3 and 3 units respectively (Figs. 4 and 6). Lastly, the activity of malic enzyme of lactating mammary gland rises to $5 \cdot 8$ units 18-21 days post partum (Matthes, Abraham \& Chaikoff, 1963), and the activity of citrate-cleavage enzyme rises to 6 units (A. F. Spencer \& J. M. Lowenstein, unpublished work).

The parallel changes in the activities of these 
two enzymes suggest that the reactions catalysed by malic enzyme and citrate-cleavage enzyme (reactions 1 and 3) both play a role in the extramitochondrial synthesis of fatty acids, the link being provided by extramitochondrial malate dehydrogenase (reaction 2) :

$$
\begin{aligned}
& \text { Citrate }+\mathrm{ATP}+\mathrm{CoA} \rightarrow \text { acetyl-CoA } \\
& + \text { oxaloacetate }+\mathrm{ADP}+\text { orthophosphate } \\
& \text { Oxaloacetate }+\mathrm{NADH} \rightarrow \text { malate }+\mathrm{NAD}^{+} \\
& \text {Malate }+\mathrm{NADP}^{+} \rightarrow \text { pyruvate }+\mathrm{CO}_{2}+\mathrm{NADPH}
\end{aligned}
$$

This proposed function of malic enzyme has the following features. (i) It provides a pathway for generating extramitochondrial NADPH from NADH. That such a pathway may occur is indicated by the finding that tissue slices incorporate substantial amounts of hydrogen from the 2-position of lactate into fatty acids (Lowenstein, 1961). (ii) It provides a metabolic role for extramitochondrial malate dehydrogenase. (iii) Incorporation of one acetyl group into long-chain fatty acid requires two molecules of NADPH. The malic enzyme reaction operating in the sequence reactions (1)-(3) could supply a maximum of $50 \%$ of the NADPH needed/acetyl group incorporated into fatty acid.

This work was supported by grants from the Medical Foundation, Boston, Mass., U.S.A., and the U.S. National Science Foundation (GB-833). M. S. K. is a predoctoral fellow of the U.S. Public Health Service (1-F1-GM-17525 AlAl). This paper is publication no. 322 of the Graduate Department of Biochemistry, Brandeis University.

\section{REFERENCES}

Baker, N., Chaikoff, I. L. \& Schusdek, A. (1952). J. biol. Chem. 194, 435.

Beatty, C. H. \& West, E. S. (1955). J. biol. Chem. 215, 661. Bhaduri, A. \& Srere, P. A. (1963). Biochim. biophys. Acta, $70,221$.

Blumenthal, M. D., Abraham, S. \& Chaikoff, I. L. (1964). Arch. Biochem. Biophys. 104, 225.

Brady, R. O. \& Gurin, S. (1950). J. biol. Chem. 187, 589.

Brady, R. O., Lukens, F. D. W. \& Gurin, S. (1951). J. biol. Chem. 193, 459.

Bremer, J. (1962). J. biol. Chem. 237, 2228.

Chaikoff, I. L. (1953). Harvey Lect. 47, 99.

Chernick, S. S. \& Chaikoff, I. L. (1950). J. biol. Chem. 186, 535.

Chernick, S. S. \& Chaikoff, I. L. (1951). J. biol. Chem. 188, 389.
Chernick, S. S., Chaikoff, I. L. \& Abraham, S. (1951). J. biol. Chem. 193, 793.

Cori, C. F. (1925). J. biol. Chem. 66, 691.

Exton, J. H. \& Edson, N. L. (1964). Biochem. J. 91, 478.

Fitch, W. M. \& Chaikoff, I. L. (1962). Biochim. biophys. Acta, 57, 588.

Fitch, W. M., Hill, R. \& Chaikoff, I. L. (1959a). J. biol. Chem. 234, 1048.

Fitch, W. M., Hill, R. \& Chaikoff, I. L. (1959b). J. biol. Chem. 234, 2811.

Folley, S. J. \& Greenbaum, A. L. (1960). Brit. med. Bull. 16, 228.

Fritz, I. B. (1963). Advanc. Lipid Res. 1, 285.

Harlan, W. R. \& Wakil, S. J. (1963). J. biol. Chem. 238, 3216.

Hotta, S. \& Chaikoff, I. L. (1952). J. biol. Chem. 198, 895.

Howard, C. F. \& Lowenstein, J. M. (1964). Biochim. biophys. Acta, 84, 226.

Korff, R. W. von (1953). J. biol. Chem. 203, 265.

Kornacker, M. \& Lowenstein, J. M. (1963). Biochem. J. 89, 27 P.

Kornacker, M. S. \& Lowenstein, J. M. (1964a). Science, 144, 1027.

Kornacker, M. S. \& Lowenstein, J. M. (1964b). Biochim. biophys. Acta, 84, 490.

Kornacker, M. S. \& Lowenstein, J. M. (1965). Biochem. J. 94, 209.

Lequin, H. C. \& Steyn-Parvé, E. P. (1962). Biochim. biophys. Acta, 58, 439.

Lowenstein, J. M. (1961). J. biol. Chem. 236, 1213.

Lowenstein, J. M. (1963). In Oxygen in the Animal Organism, p. 163. Ed. by Dickens, F. \& Neill, E. Oxford: Pergamon Press Ltd.

Lowenstein, J. M. (1965). In Recent Research on Carnitine, p. 97. Ed. by Wolf, G. Cambridge, Mass.: The Massachusetts Institute of Technology Press.

Lowenstein, J. M., Spencer, A. F. \& Kornacker, M. (1964). Abstr. 6th int. Congr. Biochem., New York, vol. 9, p. 726.

Matthes, K. J., Abraham, S. \& Chaikoff, I. L. (1963). Biochim. biophys. Acta, 71, 568.

Park, J. T. \& Johnson, M. J. (1949). J. biol. Chem. 181, 149.

Renold, A. E., Hastings, A. B., Nesbett, F. B. \& Ashmore, J. (1955). J. biol. Chem. 213, 135.

Sharma, C., Manjeshwar, R. \& Weinhouse, S. (1963). J. biol. Chem. 238, 3840.

Shrago, E., Lardy, H. A., Nordlie, R. C. \& Foster, D. O. (1963). J. biol. Chem. 238, 3188.

Spencer, A. F., Corman, L. \& Lowenstein, J. M. (1964). Biochem. J. 93, 378.

Spencer, A. F. \& Lowenstein, J. M. (1962). J. biol. Chem. 237, 3640.

Stetten, D. \& Boxer, G. E. (1944). J. biol. Chem. 156, 271.

Viñuela, E., Salas, M. \& Sols, A. (1963). J. biol. Chem. 238, PC 1175.

Walker, D. G. \& Rao, S. (1964). Biochem. J. 90, 360.

Wieland, O., Neufeldt, I., Numa, S. \& Lynen, F. (1963). Biochem. Z. 336, 455. 